\title{
What Is the Optimal Monotherapy in Korean Drug-Naïve Type 2 Diabetic Patients?: The Practical Evidence of Antidiabetic Monotherapy Study
}

\author{
Ji Hun Choi, Won-Young Lee \\ Division of Endocrinology and Metabolism, Department of Internal Medicine, Kangbuk Samsung Hospital, Sungkyunkwan University School of Medicine, \\ Seoul, Korea
}

The prevalence of diabetes worldwide is continually increasing, and even more people are affected by prediabetes. As a result of scientific and economic growth, the number of diabetes patients has increased rapidly from less than $1 \%$ in the 1970 s to more than $10 \%$ in the mid-1990s; in Korea, the incidence is projected to be $15 \%$ to $20 \%$ by 2030 [1]. Before 1996, only sulfonylureas and insulin were available for the treatment of type 2 diabetes mellitus (T2DM). Since then, drugs of several other classes have been developed.

Hypoglycemic agents in T2DM should be chosen based upon the medical needs and treatment goals of the patient, potency of the agent in achieving treatment goals, tolerability, side effects, cost-effectiveness, ease of administration, and other beneficial extraglycemic effects.

The biguanide drug metformin was introduced for the treatment of T2DM in Europe in 1957 but was not approved in the United States until 1995 because of fear of lactic acidosis. However, recent studies have suggested that metformin is safe unless the patient's estimated glomerular filtration rate falls to $<30 \mathrm{~mL} / \mathrm{min}$ [2]. The drug's major effect is to decrease hepatic glucose output and lower fasting glycemia [3]. In the United Kingdom Prospective Diabetes Study (UKPDS), metformin was shown to reduce cardiovascular events [4]; the risk of progression from prediabetes to T2DM decreased by $31 \%$ in the
Diabetes Prevention Program (DPP) cohort [5]. Given these benefits, metformin should be considered a first-line agent in the treatment of T2DM.

The thiazolidinediones (TZDs) rosiglitazone and pioglitazone are approved for monotherapy and combination treatment of T2DM. These medications increase the sensitivity of muscle, fat and liver to both endogenous and exogenous insulin ("insulin sensitizers") [6]. In addition, TZDs have been shown to preserve or improve $\beta$-cell secretory function in patients with T2DM. TZD monotherapy lowers A1C levels by 0.5 percent to 1.4 percent. The most common side effects of TZDs are weight gain and fluid retention, along with peripheral edema and an increased risk for congestive heart failure $[7,8]$. Several meta-analyses have suggested a $30 \%$ to $40 \%$ relative increase in the risk for myocardial infarction $[9,10]$ with rosiglitazone; however, reanalysis by the Food and Drug Administration found no significant increase in serious ischemia in patients treated with rosiglitazone [11]. In contrast, the Prospective Pioglitazone Clinical Trial in macrovascular events (PROactive) demonstrated no significant effects of pioglitazone compared with placebo on primary cardiovascular disease outcome [12]. A retrospective analysis of the Veterans Affairs Diabetes Trial (VADT) cohort, which included nearly 40,000 patients treated with metformin, sulfonylurea or TZDs, found
Corresponding author: Won-Young Lee

Division of Endocrinology and Metabolism, Department of Internal

Medicine, Kangbuk Samsung Hospital, Sungkyunkwan University School of

Medicine, 108 Pyeong-dong, Jongno-gu, Seoul 110-746, Korea

E-mail: drlwy@hanmail.net
This is an Open Access article distributed under the terms of the Creative Commons Attribution Non-Commercial License (http://creativecommons.org/licenses/by-nc/3.0/) which permits unrestricted non-commercial use, distribution, and reproduction in any medium, provided the original work is properly cited. 
no difference in cardiovascular outcomes among users of the three classes of drugs [13]. Although the meta-analyses discussed above are not conclusive regarding the potential cardiovascular risk associated with this medication, rosiglitazone should be used with caution.

The sulfonylureas are very commonly used because they are readily available, affordable and have convenient dosing instructions [14]. Although the onset of the glucose-lowering effect of sulfonylurea monotherapy is relatively rapid compared with TZDs, the glycemic durability is not as good as monotherapy with a TZD or metformin [15]. A recently published, observational cohort study also stated that in a standard clinical setting, insulin secretagogues are associated with increased failure rates in comparison with metformin, even after adjusting for controllable confounders [16]. Sulfonylureas have a primary failure rate of $20 \%$ and a secondary failure rate of $5 \%$ to $10 \%$ per year of treatment [17].

The Practical Evidence of Anti-diabetic Monotherapy (PEAM) study, which evaluated the efficacy of glimepiride, metformin and rosiglitazone as an initial treatment for drugnaive T2DM, was a 48-week randomized, controlled study that included 349 Korean patients and was conducted by Yoon et al. [18]. This study found that there were no statistical differences in the efficacy of these drugs as monotherapy in drugnaive Korean T2DM patients. In concordance with previous reports of anti-diabetic regimens $[3,6,14]$, the main side effect with metformin was diarrhea, edema and weight gain with rosiglitazone, and symptomatic hypoglycemia and weight gain with glimepiride. Yoon et al. did not observe the time course of metabolic changes during the study. Assessing metabolic changes that include lipid parameters is important in evaluating the metabolic effect of anti-diabetic agents and a multi-factorial intervention as a diabetic treatment strategy for improving cardiovascular outcome. Additionally, this study was designed to use rosiglitazone, which has been practically thrown out in market in recent years. It is not clear whether the scheduled up titration performed in the present study is a suitable and optimal method for Koreans. A relatively high drop-out rate was also observed. Therefore, these limitations can lessen the value of the information gained from this study in selecting an oral hypoglycemic agent in Korean diabetic patients. Despite these limitations, the importance of this study is that it is the first randomized, controlled trial to evaluate the efficacy of commonly used oral hypoglycemic agents in Korean T2DM patients. The study was well-designed and is one of the few studies in which commonly used anti-diabetic drugs were directly compared among drug-naïve diabetic patients.

Newer agents including incretins are less likely to produce adverse effects such as symptomatic hypoglycemia, are currently being broadly used in drug-naïve T2DM patients. Several studies evaluating the efficacy and beneficial and adverse effects of these agents are currently ongoing worldwide. Future studies are therefore needed to evaluate these new agents as a monotherapy in Korean T2DM patients. While this study found that about $30 \%$ of participants remained in an inadequate glycemic control state, a lack of consensus remained in regard to the choice of a combination regimen to optimize glycemic control. As the authors have noted, a more detailed subgroup analysis and further investigation, particularly as it relates to the combination regimens, are required.

\section{REFERENCES}

1. Korea Health and Welfare Ministry. 2001 The Korean national health nutrition examination survey. Seoul: Korea Health and Welfare Ministry; 2003.

2. Salpeter S, Greyber E, Pasternak G, Salpeter E. Risk of fatal and nonfatal lactic acidosis with metformin use in type 2 diabetes mellitus. Cochrane Database Syst Rev 2006;(1): CD002967.

3. Bailey CJ, Turner RC. Metformin. N Engl J Med 1996;334:574-9. 4. UK Prospective Diabetes Study (UKPDS) Group. Effect of intensive blood-glucose control with metformin on complications in overweight patients with type 2 diabetes (UKPDS 34). Lancet 1998;352:854-65.

5. Knowler WC, Barrett-Connor E, Fowler SE, Hamman RF, Lachin JM, Walker EA, Nathan DM; Diabetes Prevention Program Research Group. Reduction in the incidence of type 2 diabetes with lifestyle intervention or metformin. N Engl J Med 2002;346:393-403.

6. Yki-Jarvinen H. Thiazolidinediones. N Engl J Med 2004;351: 1106-18.

7. Home PD, Pocock SJ, Beck-Nielsen H, Gomis R, Hanefeld M, Jones NP, Komajda M, McMurray JJ; RECORD Study Group. Rosiglitazone evaluated for cardiovascular outcomes--an interim analysis. N Engl J Med 2007;357:28-38.

8. Singh S, Loke YK, Furberg CD. Thiazolidinediones and heart failure: a teleo-analysis. Diabetes Care 2007;30:2148-53.

9. Nissen SE, Wolski K. Effect of rosiglitazone on the risk of myocardial infarction and death from cardiovascular causes. N Engl J Med 2007;356:2457-71. 
10. Singh S, Loke YK, Furberg CD. Long-term risk of cardiovascular events with rosiglitazone: a meta-analysis. JAMA 2007;298: 1189-95.

11. Bloomgarden ZT. Approaches to treatment of type 2 diabetes. Diabetes Care 2008;31:1697-703.

12. Dormandy JA, Charbonnel B, Eckland DJ, Erdmann E, MassiBenedetti M, Moules IK, Skene AM, Tan MH, Lefebvre PJ, Murray GD, Standl E, Wilcox RG, Wilhelmsen L, Betteridge J, Birkeland K, Golay A, Heine RJ, Koranyi L, Laakso M, Mokan M, Norkus A, Pirags V, Podar T, Scheen A, Scherbaum W, Schernthaner G, Schmitz O, Skrha J, Smith U, Taton J; PROactive investigators. Secondary prevention of macrovascular events in patients with type 2 diabetes in the PROactive Study (PROspective pioglitAzone Clinical Trial In macroVascular Events): a randomised controlled trial. Lancet 2005;366:1279-89.

13. Kahler KH, Rajan M, Rhoads GG, Safford MM, Demissie K, Lu SE, Pogach LM. Impact of oral antihyperglycemic therapy on all-cause mortality among patients with diabetes in the Veterans Health Administration. Diabetes Care 2007;30:1689-93.

14. Groop LC. Sulfonylureas in NIDDM. Diabetes Care 1992;15: 737-54.
15. Kahn SE, Haffner SM, Heise MA, Herman WH, Holman RR, Jones NP, Kravitz BG, Lachin JM, O’Neill MC, Zinman B, Viberti G; ADOPT Study Group. Glycemic durability of rosiglitazone, metformin, or glyburide monotherapy. N Engl J Med 2006;355:2427-43.

16. Pala L, Monami M, Lamanna C, Cresci B, Colombi C, Bardini G, Sposato J, Marchionni N, Rotella CM, Mannucci E. Failure to metformin and insulin secretagogue monotherapy: an observational cohort study. Acta Diabetol 2010;47(Suppl 1):7-11.

17. Wright A, Burden AC, Paisey RB, Cull CA, Holman RR; U.K. Prospective Diabetes Study Group. Sulfonylurea inadequacy: efficacy of addition of insulin over 6 years in patients with type 2 diabetes in the U.K. Prospective Diabetes Study (UKPDS 57). Diabetes Care 2002;25:330-6.

18. Yoon KH, Shin JA, Kwon HS, Lee SH, Min KW, Ahn YB, Yoo SJ, Ahn KJ, Park SW, Lee KW, Sung YA, Park TS, Kim MS, Kim YK, Nam MS, Kim HS, Park IB, Park JS, Woo JT, Son HY. Comparison of the efficacy of glimepiride, metformin, and rosiglitazone monotherapy in Korean drug-naïve type 2 diabetic patients: the practical evidence of antidiabetic monotherapy study. Diabetes Metab J 2011;35:26-33. 